\title{
Relative validity of an FFQ for pre-school children in the mother-child 'Rhea' birth cohort in Crete, Greece
}

\author{
Vasiliki Leventakou, Vaggelis Georgiou, Leda Chatzi and Katerina Sarri* \\ Department of Social Medicine, Faculty of Medicine, University of Crete, PO Box 2208, Heraklion 71003, Crete, \\ Greece
}

Submitted 11 June 2013: Final revision received 16 January 2014: Accepted 13 February 2014: First published online 28 March 2014

\begin{abstract}
Objective: To examine the relative validity of an FFQ based on parental report for pre-school children in the mother-child 'Rhea' birth cohort.

Design: The children's mothers completed an FFQ that referred to the children's dietary intake for the previous year by telephone interview. Mothers completed also three food records, two on weekdays and one on a weekend day. Spearman correlation coefficients were calculated for the energy-adjusted values. Weighted kappa statistics $\left(\kappa_{\mathrm{W}}\right)$ and the Bland-Altman technique were used to test the degree of agreement between the two dietary methods.

Setting: Heraklion, Crete, Greece, 2011-2012.

Subjects: A total of ninety-nine mothers (corresponding to fifty-one boys and fortyeight girls) participated in the validation study.

Results: The mean and median values of all food group and nutrient intakes did not differ significantly between the two dietary methods. Overall, fair agreement was observed between the FFQ and the food records for ranking participants based on their intake, with $\kappa_{\mathrm{w}}$ ranging from 0.21 to 0.40 for most foods and nutrients. On average, $88 \%$ of participants were classified into the same or adjacent tertiles for nutrient and food group intakes by both dietary methods. The degree of agreement was also confirmed by the visual examination of the Bland-Altman plots.

Conclusions: The study indicates that the Rhea 4 years FFQ is a relatively accurate tool for assessing habitual food group and nutrient intakes among pre-school children in Crete, Greece.
\end{abstract}

Keywords

Validation

FFQ

Pre-school children

Food records
Early-life nutrition has been established not only as a key component for the maintenance of lifelong health ${ }^{(1)}$, but also as a major determinant of chronic diseases such as type 2 diabetes $^{(2)}, \mathrm{CVD}^{(3,4)}$, obesity ${ }^{(5,6)}$, hypertension ${ }^{(7,8)}$, allergies $^{(9,10)}$ and certain cancers ${ }^{(11)}$. Contrary to other risk factors, diet is potentially modifiable, especially in childhood. It is therefore important to assess dietary intake with valid tools in order to establish the role early nutrition plays in chronic disease promotion or prevention.

In large-scale population studies, it is a continuous challenge to assess diet during childhood. FFQ, $24 \mathrm{~h}$ recalls and food records (FR) are well-known dietary assessment instruments based on parental report ${ }^{(12)}$. Although accurate, $24 \mathrm{~h}$ recalls and FR are time consuming and costly ${ }^{(13)}$. On the other hand, FFQ are designed to measure long-term intake and are a less expensive and lengthy option ${ }^{(14,15)}$. In order to assess the relative validity of an FFQ, $24 \mathrm{~h}$ recalls and FR are usually used as they do not require participant literacy and provide high levels of specificity $^{(1,13,16,17)}$.
The aim of the present study was to examine the relative validity of an FFQ designed for pre-school children aged 4 years in the region of Heraklion, Crete, Greece, against $3 \mathrm{~d}$ FR.

\section{Methods}

\section{Validation study participants and design}

The present study is a sub-project of the mother-child 'Rhea' study in Crete ${ }^{(18)}$. In summary, the Rhea study has been following a total of 1317 women and their offspring since 2007-2008. Healthy children participating in the Rhea cohort were invited to take part in the validation study when they came for their routine follow-up at 4 years (2011-2012), which included children's dietary assessment via an FFQ. The Rhea cohort has obtained dietary information for mothers and children at different time points up to 4 years: during pregnancy, at 9 and 18 months postpartum and recently at 4 years. The mothers who agreed to participate in 
the validation study were asked to keep a $3 \mathrm{~d}$ weighed FR for their children. Of the 204 mothers who were invited to participate in the validation study, 104 completed the FR. Five of them did not complete the FR correctly and thus were excluded from the analysis. The final number of participants included in the validation study was ninety-nine children (fifty-one boys, forty-eight girls). Information on child and maternal characteristics such as weight, height, lifestyle characteristics, parity, marital status, smoking status and maternal education were gathered at enrolment and during the 4-year follow-up.

The study was conducted according to the guidelines laid down in the Declaration of Helsinki and all procedures involving human subjects were approved by the ethical committee of the University Hospital in Heraklion, Crete, Greece. Written informed consent was obtained from all women participating in the study.

\section{Dietary assessment}

The Rhea follow-up FFQ is a newly developed questionnaire designed to assess habitual dietary intake in preschool children. The Rhea follow-up FFQ was completed by telephone interview where parents were asked to recall their child's diet for the previous year. The Rhea follow-up FFQ is a semi-quantitative questionnaire that asks about the intake of 118 food items. It also includes nine supplementary questions regarding type of meals during the day (breakfast, morning snack, lunch, afternoon snack, dinner, evening snack), use of dietary supplements (brand name of product, number of daily doses, time period of intake), type of fat used for cooking, medical conditions that can affect diet (i.e. high cholesterol), frequency of meals consumed in restaurants or takeaways, and television viewing during meals. The interviewer could also add anything else consumed by the child that was not included in the existing list of the 118 food items. Mothers could choose from one or two portion sizes, and reported the child's frequency of intake (times per day, week, month or year, or never). Seasonality of consumption could also be reported in all food items.

In the validation study, the FR was self-administered by the participants who received the FR via post (including a prepaid envelope) together with instructions on how to complete it. Additional information and clarifications were provided by telephone. Parents were asked to feed their child his/her normal diet, to weigh and record all foods, beverages and dietary supplements consumed by their child during two consecutive weekdays and one weekend day, and were also asked to collect information about their child's diet from the caregiver or day nursery. Upon collection, the FR were checked for completeness by a nutritionist.

\section{Analysis of food consumption data}

In the present study, FFQ and FR data were converted into daily intakes of foods and nutrients using the UK food tables (McCance \& Widdowson's The Composition of
Foods, 6th summary edition) and standard Greek recipes for complex mixed dishes. For the FR, the mean of the three recording days was assessed. The dietary intake data were analysed by using a software program developed at the Department of Applied Information Technology and Multimedia, TEI-Crete, Heraklion, Crete, Greece.

\section{Statistical analysis}

Pearson's $\chi^{2}$ test for independence was used to compare the number of participants classified according to maternal education, marital status, residence, smoking status, parity and child gender in the validation study sample and the Rhea sample, as well as in the validation study sample and those who did not send back FR (non-responders). The Mann-Whitney $U$ test was used to compare both maternal and child age and BMI. The nutrients presented in the current study were extracted from food sources only. The differences in food group and nutrient intakes between the Rhea follow-up FFQ and the FR were tested with the Wilcoxon signed-rank test in order to identify systematic bias. The relationship between the two dietary methods was assessed by using the Spearman rank correlation coefficient.

The agreement between the two methods was analysed as proposed by Bland and Altman ${ }^{(19)}$, using a graphical technique and simple calculations for all nutrient and food group intakes. This was accomplished by plotting the differences in intakes between the FFQ and FR $v$. the mean intakes of the FFQ and FR. The $95 \%$ limits of agreement (mean difference $\pm 1.96 \mathrm{SD}$ ) show how well the two methods agree. This was performed for all nutrients and food groups, and some of the plots are presented herein. Following the graphical representation, when the standard error increased at higher measured values, the detection of heteroscedasticity was possible. The degree of heteroscedasticity was examined using Kendall's tau correlation $(\tau)$ between the absolute differences and the mean of the two dietary methods. When $\tau>0 \cdot 1$ the data are heteroscedastic and when $\tau<0 \cdot 1$ or negative the data are homoscedastic.

Furthermore, agreement on a categorical level was examined by classification of food and nutrient intakes into the same (correct classification), adjacent or opposite tertiles (gross misclassification) by the FFQ and the FR for energyadjusted intakes. The agreement between the two dietary methods was additionally assessed with the weighted kappa statistic $\left(\kappa_{\mathrm{w}}\right)$ based on the Fleiss-Cohen quadratic weighting scheme and $95 \%$ confidence intervals are presented ${ }^{(20)}$. The following ranges describe the different degrees of agreement: $\kappa_{\mathrm{w}}=0.00$ to 0.20 (slight agreement), $\kappa_{\mathrm{w}}=0.21$ to 0.40 (fair agreement), $\kappa_{\mathrm{w}}=0.41$ to 0.60 (moderate agreement), $\kappa_{\mathrm{w}}=0.61$ to 0.80 (substantial agreement) and $\kappa_{\mathrm{w}}=0.81$ to 1.00 (almost perfect agreement) ${ }^{(21)}$.

All analyses were performed with crude data and energy-adjusted data using the residual method ${ }^{(22)}$.

The significance level was set at 5\% and a two-sided alternative hypothesis. All statistical analyses were performed 
using the statistical software packages IBM SPSS Statistics version $20 \cdot 0$ and STATA SE version 13.0.

\section{Results}

The validation study participants were compared with the total population of the Rhea study (Table 1). No differences were found between these two groups regarding several sociodemographic characteristics such as maternal and child age, maternal education and origin, child gender, marital status, residence, maternal and child BMI and maternal parity. Similarly, no differences were found between the validation study participants and those who, though enrolled, did not send FR (non-responders), with the exception of smoking status (data not shown).

The mean age of mothers participating in the current study was 33.6 years, $36.4 \%$ of them were highly educated and the great majority were married and of Greek origin (87.9\% and $96.0 \%$, respectively; Table 1). The children participating in the validation study were 3.7 years old with a mean BMI of $16 \cdot 5 \mathrm{~kg} / \mathrm{m}^{2}$.

Table 2 presents the mean and median daily intakes of food groups and nutrients as assessed by the FFQ and the
FR. In particular, the FFQ recorded higher intakes of vegetables, fruits, milk and eggs, while lower intakes were recorded for sugar preserves and confectionery, pulses, poultry and red meat. For all nutrients and food groups, according to the Wilcoxon signed-rank test, the mean difference between the methods (systematic bias) was not statistically significant. The average energy-adjusted correlation coefficient between the two dietary assessment methods for food groups was $0 \cdot 380$, ranging from $r=0 \cdot 109$ for poultry to $r=0.671$ for milk. The mean and median intakes of all nutrients were larger when assessed by the FFQ than by the FR (Table 2). The average correlation between the two dietary assessment methods for nutrients was 0.315 , ranging from $r=0.099$ for total fat to $r=0.484$ for vitamin $\mathrm{B}_{12}$ and iodine. The average energy-adjusted Spearman's correlation coefficient reached statistical significance for almost all food groups and nutrients.

The differences between the FFQ and FR for absolute intakes of nutrients and foods were examined using Bland-Altman plots. The plots for all nutrients and food groups were similar to the plot for energy (Fig. 1(a)), fat (Fig. 1(d)) and carbohydrate intake (Fig. 1(e)). For all plots the $95 \%$ limits of agreement indicated fairly good agreement between the two dietary methods, although for

Table 1 Characteristics of the participants included in the validation study of the mother-child 'Rhea' birth cohort, Heraklion, Crete, Greece, 2011-2012 and comparison with the total population of the Rhea study

\begin{tabular}{|c|c|c|c|c|c|}
\hline & \multicolumn{2}{|c|}{$\begin{array}{l}\text { Validation study } \\
\qquad(n \text { 99) }\end{array}$} & \multicolumn{2}{|c|}{$\begin{array}{c}\text { Rhea } \\
(n \text { 1008) }\end{array}$} & \multirow[b]{2}{*}{$P$ value } \\
\hline & $n$ & $\%$ & $n$ & $\%$ & \\
\hline \multicolumn{5}{|l|}{ Maternal education } & 0.353 \\
\hline Low & 13 & 13.1 & 169 & $17 \cdot 7$ & \\
\hline Medium & 50 & 50.5 & 495 & $51 \cdot 8$ & \\
\hline High & 36 & $36 \cdot 4$ & 292 & 30.5 & \\
\hline \multicolumn{5}{|l|}{ Mother's origin } & 0.301 \\
\hline Greek & 95 & $96 \cdot 0$ & 929 & 93.3 & \\
\hline Other & 4 & 4.0 & 67 & $6 \cdot 7$ & \\
\hline \multicolumn{5}{|l|}{ Marital status } & 0.748 \\
\hline Married/engaged & 87 & 87.9 & 853 & 88.9 & \\
\hline Other & 12 & $12 \cdot 1$ & 106 & 11.1 & \\
\hline \multicolumn{5}{|l|}{ Residence } & 0.982 \\
\hline Urban & 63 & 71.6 & 555 & 71.7 & \\
\hline Rural & 25 & $28 \cdot 4$ & 219 & $28 \cdot 3$ & \\
\hline \multicolumn{5}{|l|}{ Smoking status } & $0.003^{*}$ \\
\hline Smoker & 19 & 21.6 & 292 & 12.5 & \\
\hline Non-smoker & 69 & 78.4 & 484 & 87.5 & \\
\hline \multicolumn{5}{|l|}{ Parity } & 0.268 \\
\hline Multiparous & 50 & 51.5 & 543 & 57.4 & \\
\hline Primiparous & 47 & 48.5 & 403 & 42.6 & \\
\hline \multicolumn{5}{|l|}{ Child gender } & 0.894 \\
\hline Male & 51 & 51.5 & 526 & $52 \cdot 2$ & \\
\hline \multirow[t]{2}{*}{ Female } & 48 & $48 \cdot 5$ & 482 & $47 \cdot 8$ & \\
\hline & Mean & SD & Mean & SD & $P$ value \\
\hline Maternal age (years) & 33.64 & $5 \cdot 37$ & $33 \cdot 50$ & 4.92 & 0.910 \\
\hline Maternal BMI $\left(\mathrm{kg} / \mathrm{m}^{2}\right)$ & 25.59 & 5.44 & $25 \cdot 43$ & 4.92 & 0.973 \\
\hline Child age (years) & 3.65 & 0.11 & 3.69 & 0.39 & 0.639 \\
\hline Child BMI $\left(\mathrm{kg} / \mathrm{m}^{2}\right)$ & $16 \cdot 48$ & 1.87 & $16 \cdot 43$ & 1.98 & 0.845 \\
\hline
\end{tabular}

Missing values have been excluded (pair-wise: validation study, Rhea): maternal education ( $n 0, n$ 52); Greek origin ( $n$ 0, $n$ 12); marital status ( $n$ 0, $n$ 49); residence $(n 11, n 234)$; smoking status $(n 11, n 232)$; parity $(n 2, n 62)$; child gender $(n 0, n 0)$.

*Statistically significant difference $(P<0.05)$ based on Mann-Whitney $U$ test for two independent samples and Pearson's $\chi^{2}$ test for independence. 
Table 2 Daily food and nutrient intakes assessed by the FFQ and the $3 \mathrm{~d}$ food record (FR), and differences between both methods, among pre-school children (fifty-one boys and forty-eight girls) in the validation study of the mother-child 'Rhea' birth cohort, Heraklion, Crete, Greece, 2011-2012

\begin{tabular}{|c|c|c|c|c|c|c|c|c|c|c|c|c|}
\hline & \multirow[b]{2}{*}{$n$} & \multicolumn{4}{|c|}{ FFQ } & \multicolumn{4}{|c|}{ FR } & \multirow{2}{*}{$\begin{array}{c}\text { Difference } \\
\text { (FFQ - FR) } \\
P \text { value† }\end{array}$} & \multicolumn{2}{|c|}{ Spearman's correlation $r$} \\
\hline & & Mean & SD & Median & IQR & Mean & SD & Median & IQR & & Unadjusted & Energy adjusted \\
\hline \multicolumn{13}{|l|}{ Food groups } \\
\hline $\begin{array}{l}\text { Sugar preserves and } \\
\text { confectionery }(\mathrm{g})\end{array}$ & 98 & $45 \cdot 0$ & $27 \cdot 6$ & $40 \cdot 3$ & $35 \cdot 0$ & 51.4 & $37 \cdot 4$ & $42 \cdot 9$ & $50 \cdot 0$ & 0.716 & $0.463^{*}$ & $0.437^{*}$ \\
\hline Vegetables (g) & 99 & $156 \cdot 0$ & $76 \cdot 9$ & $145 \cdot 1$ & $86 \cdot 2$ & 94.6 & $60 \cdot 0$ & $91 \cdot 2$ & 93.9 & 0.936 & $0.362^{*}$ & $0.295^{\star}$ \\
\hline Fruits (g) & 94 & $179 \cdot 1$ & $103 \cdot 3$ & $154 \cdot 1$ & $163 \cdot 0$ & 138.9 & $107 \cdot 2$ & $125 \cdot 8$ & 148.5 & 0.998 & $0.505^{\star}$ & $0.597^{\star}$ \\
\hline Pulses (g) & 51 & $6 \cdot 4$ & 3.6 & 5.5 & $4 \cdot 1$ & $11 \cdot 2$ & $7 \cdot 4$ & 8.5 & $9 \cdot 0$ & 0.866 & $0.318^{*}$ & $0.322^{*}$ \\
\hline Milk (g) & 99 & $423 \cdot 0$ & $247 \cdot 1$ & $408 \cdot 0$ & $251 \cdot 7$ & $348 \cdot 7$ & 161.9 & $316 \cdot 7$ & $218 \cdot 1$ & 0.264 & $0.622^{*}$ & $0.671^{*}$ \\
\hline Poultry (g) & 62 & $13 \cdot 8$ & 8.2 & $12 \cdot 3$ & 8.6 & 31.3 & $17 \cdot 9$ & $28 \cdot 3$ & 23.1 & 0.656 & 0.038 & 0.109 \\
\hline Red meat $(\mathrm{g})$ & 99 & 24.4 & $12 \cdot 8$ & 21.9 & 14.9 & $32 \cdot 4$ & $21 \cdot 0$ & $29 \cdot 1$ & 29.7 & 0.398 & 0.183 & $0.253^{*}$ \\
\hline Eggs (g) & 88 & $20 \cdot 2$ & 11.5 & $20 \cdot 8$ & $17 \cdot 7$ & $18 \cdot 7$ & 13.9 & $16 \cdot 7$ & $16 \cdot 3$ & 0.591 & $0 \cdot 384^{*}$ & $0.427^{\star}$ \\
\hline \multicolumn{13}{|l|}{ Nutrients } \\
\hline Protein $(\mathrm{g})$ & 99 & $60 \cdot 7$ & 13.7 & $58 \cdot 1$ & 17.4 & $54 \cdot 8$ & $11 \cdot 7$ & $53 \cdot 6$ & 13.4 & 0.821 & $0 \cdot 242^{*}$ & $0.338^{*}$ \\
\hline Carbohydrate $(\mathrm{g})$ & 99 & $161 \cdot 8$ & $35 \cdot 1$ & $162 \cdot 2$ & $45 \cdot 8$ & $136 \cdot 3$ & 38.4 & $132 \cdot 5$ & $49 \cdot 6$ & 0.812 & 0.160 & 0.162 \\
\hline Total fat (g) & 99 & 78.4 & $19 \cdot 7$ & $78 \cdot 8$ & $22 \cdot 8$ & 71.7 & $19 \cdot 2$ & 71.6 & $24 \cdot 2$ & 0.589 & 0.178 & 0.099 \\
\hline MUFA (per $100 \mathrm{~g}$ ) & 99 & $28 \cdot 6$ & 8.4 & $27 \cdot 4$ & $10 \cdot 3$ & $25 \cdot 8$ & 8.9 & $25 \cdot 0$ & $11 \cdot 6$ & 0.505 & $0 \cdot 129$ & $0.211^{*}$ \\
\hline PUFA (per $100 \mathrm{~g}$ ) & 99 & $5 \cdot 2$ & 1.5 & $5 \cdot 2$ & 1.6 & $5 \cdot 0$ & 1.9 & 4.8 & $2 \cdot 5$ & 0.834 & 0.156 & $0.352^{*}$ \\
\hline SFA (per $100 \mathrm{~g}$ ) & 99 & 33.6 & 8.7 & 32.4 & $11 \cdot 2$ & $29 \cdot 1$ & 7.9 & $29 \cdot 1$ & $11 \cdot 2$ & 0.975 & 0.175 & 0.177 \\
\hline Vitamin $B_{12}(\mu \mathrm{g})$ & 99 & $5 \cdot 7$ & 3.0 & $5 \cdot 7$ & 4.4 & 4.0 & $2 \cdot 2$ & $3 \cdot 7$ & $2 \cdot 8$ & 0.562 & $0.411^{*}$ & $0.484^{*}$ \\
\hline Vitamin C (mg) & 99 & $110 \cdot 2$ & $46 \cdot 8$ & $96 \cdot 5$ & $77 \cdot 0$ & 71.9 & $41 \cdot 8$ & 69.5 & $52 \cdot 6$ & 0.802 & $0.342^{*}$ & $0.434^{*}$ \\
\hline Folate $(\mu \mathrm{g})$ & 99 & $222 \cdot 1$ & $56 \cdot 2$ & 218.4 & $70 \cdot 8$ & $163 \cdot 8$ & $57 \cdot 2$ & $159 \cdot 8$ & $70 \cdot 5$ & 0.724 & $0.268^{*}$ & $0.338^{*}$ \\
\hline $\mathrm{Zn}(\mathrm{mg})$ & 99 & $7 \cdot 0$ & 1.6 & $6 \cdot 8$ & $2 \cdot 0$ & $6 \cdot 0$ & $1 \cdot 3$ & 5.8 & 1.8 & 0.761 & 0.159 & $0.322^{*}$ \\
\hline $\mathrm{Ca}(\mathrm{mg})$ & 99 & $1184 \cdot 5$ & $360 \cdot 0$ & $1136 \cdot 2$ & $406 \cdot 6$ & $968 \cdot 7$ & $289 \cdot 0$ & $965 \cdot 2$ & $377 \cdot 6$ & 0.772 & $0.447^{*}$ & $0.379^{*}$ \\
\hline $\mathrm{Fe}(\mathrm{mg})$ & 99 & 7.9 & $2 \cdot 6$ & 7.5 & $2 \cdot 7$ & $6 \cdot 7$ & 2.9 & $6 \cdot 5$ & $3 \cdot 1$ & 0.989 & 0.134 & $0.222^{*}$ \\
\hline lodine $(\mu \mathrm{g})$ & 99 & $191 \cdot 2$ & 94.9 & 184.8 & $125 \cdot 4$ & 153.9 & $69 \cdot 0$ & 144.4 & $70 \cdot 0$ & 0.287 & $0.411^{*}$ & $0.484^{*}$ \\
\hline$P(m g)$ & 99 & $1255 \cdot 6$ & 311.0 & $1189 \cdot 1$ & 398.2 & 1074.0 & $262 \cdot 3$ & 1044.5 & $349 \cdot 1$ & 0.655 & $0.404^{*}$ & $0.401^{*}$ \\
\hline
\end{tabular}

IQR, interquartile range.

*Statistically significant Spearman's $r(P<0.05)$.

†Wilcoxon signed-rank test, adjusted for energy intake $(P<0.05$ indicates significance).

energy intake the limits of agreement were wide. The Bland-Altman analysis showed a positive mean difference, indicating that the FFQ recorded higher intakes than the FR. The plots for vegetable (Fig. 1(b)) and fruit intake (Fig. 1(c)) indicate a suspicion of data being heteroscedastic. This was examined using Kendall's $\tau$ correlation, which was found not to be statistically significant for fruits $(\tau=-0.01$; $P=0.904)$ and vegetables $(\tau=0.08 ; P=0 \cdot 112)$. Heteroscedasticity was tested for all nutrients and food groups with no significant results.

Cross-classification into tertiles showed that the percentage of participants correctly classified ranged from $37.3 \%$ for $\mathrm{Fe}$ to $58.6 \%$ for iodine, as regards nutrient intakes (Table 3 ). For food group intakes, the percentage of participants correctly classified ranged from $36.5 \%$ for poultry to $58.5 \%$ for both milk and fruits. On average, $89 \%$ of children were classified by both methods into the same or adjacent tertiles according to their food group intakes and $87 \%$ according to their nutrient intakes.

Overall, the agreement between the FFQ and the FR was generally moderate when tested with $\kappa_{\mathrm{w}}$ (Table 3) since most food groups and nutrients reached statistical significance, although few moderate agreements were observed. After adjustment for total energy intake, the $\kappa_{\mathrm{w}}$ values ranged from 0.12 (poultry) to 0.62 (milk) for the food groups and from 0.12 (SFA) to 0.48 (iodine) for the nutrients. Substantial agreement was observed for milk $\left(\kappa_{\mathrm{w}}=0.62\right)$, while moderate agreement was observed for fruits, vitamin $\mathrm{B}_{12}$ and iodine $\left(\kappa_{\mathrm{w}}=0.57,0.44\right.$ and 0.48 , respectively; Table 3 ).

\section{Discussion}

The present study is the first validation study of an FFQ addressed to pre-school children in Greece. The participants were selected from the population for which the questionnaire was designed, and there were no differences regarding sociodemographic characteristics between the study participants and the overall population of the Rhea cohort, with the exception of maternal smoking status.

The average correlations of energy-adjusted data between the FFQ and FR found in the present study ( $r=0.38$ for food groups and $r=0.31$ for nutrients) are low to moderate but comparable to those reported in other validation studies. In a validation study conducted by Blum et al. ${ }^{(23)}$ on pre-school children aged $1-5$ years, moderate correlations were reported for nutrients ranging from $r=0.26$ to $r=0.63$, while the average correlation was $r=0.52$. Similar correlations were found by Parrish et al. ${ }^{(24)}$, with range from $r=0.33$ to 0.42 for nutrients, in a study conducted in children aged 1-3 years. For older children aged 4-9 years, Wilson and Lewis ${ }^{(25)}$ reported correlations from 0.40 to 0.55 for nutrients. Additionally, Treiber et al. ${ }^{(12)}$ reported a mean correlation of 
(a)

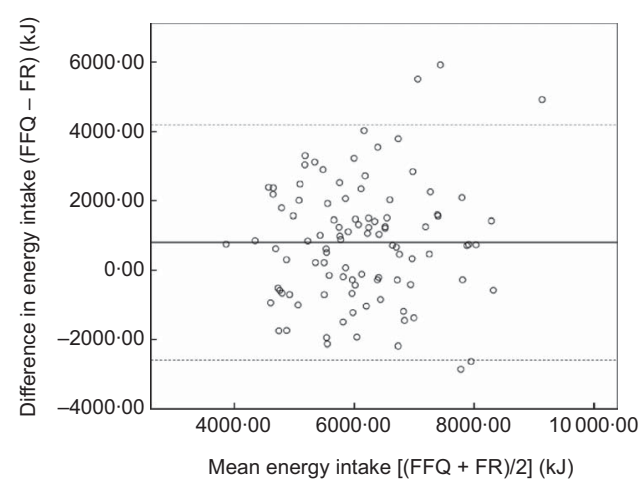

(c)

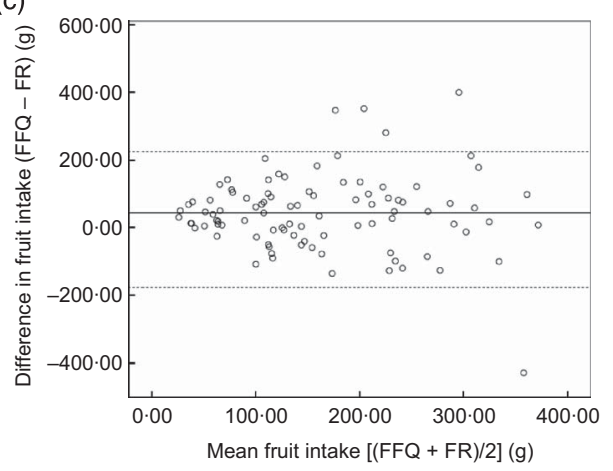

(b)

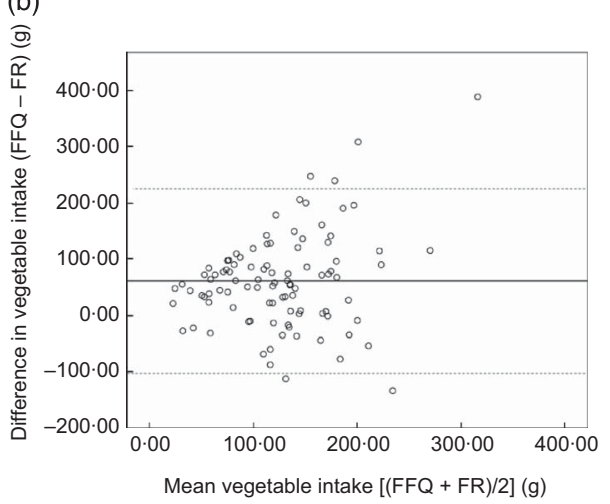

(d)

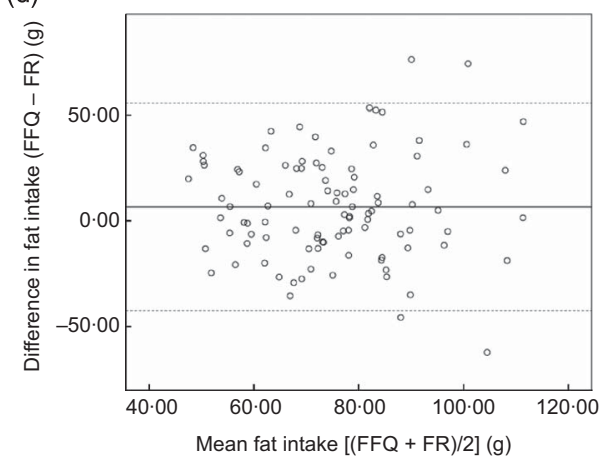

(e) क्

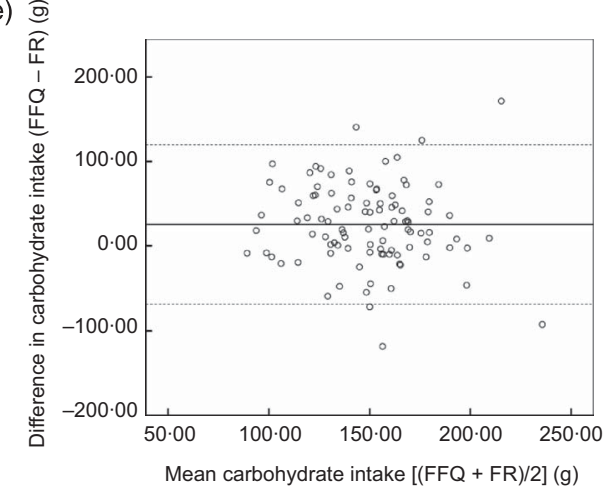

Fig. 1 Bland-Altman plots showing the agreement between the FFQ and the $3 \mathrm{~d}$ food record (FR) in estimating daily nutrient and food group intakes among pre-school children (fifty-one boys and forty-eight girls) in the validation study of the mother-child 'Rhea' birth cohort, Heraklion, Crete, Greece, 2011-2012. The difference between the two methods (FFQ - FR) is plotted $v$. the mean of the two methods $(F F Q+F R) / 2)$, where — represents the mean difference between the two dietary methods and - - - represent the $95 \%$ limits of agreement (LOA; corresponding to the mean difference $\pm 1.96 \mathrm{SD}$ ), for: (a) energy intake (mean difference $=794 \mathrm{~kJ}$ and LOA $=-2589 \mathrm{~kJ}, 4179 \mathrm{~kJ}$ ); (b) vegetable intake (mean difference $=61 \mathrm{~g}$ and $\mathrm{LOA}=-102 \mathrm{~g}, 225 \mathrm{~g}$ ); (c) fruit intake (mean difference $=45 \mathrm{~g}$ and $\mathrm{LOA}=-176 \mathrm{~g}, 226 \mathrm{~g}$ ); (d) fat intake (mean difference $=6 \mathrm{~g}$ and LOA= $-42 \mathrm{~g}, 55 \mathrm{~g}$ ); $(\mathrm{e}$ ) carbohydrate intake (mean difference $=25 \mathrm{~g}$ and LOA $=-69 \mathrm{~g}, 120 \mathrm{~g}$ )

0.67 (range: $r=0.42$ to 0.83 ) for nutrients in a study of fiftyfive children aged $3-5$ years. Weaker correlations $(r=0.48$ for total energy, $r=0.35$ for total fat and $r=0.37$ for saturated fat) were observed in a study performed by Stein et al. ${ }^{(26)}$, probably due to incorrect parental reports on dietary intake when children were not under their surveillance.

In our validation study, we found moderate agreement between the FFQ and FR as regards food groups and nutrients. Calculating solely correlations is not sufficient to give credence to the FFQ. Comparisons of tertiles are more informative than a correlation coefficient when reporting the capacity of an assessment method to rank persons with regard to their intake ${ }^{(27)}$. In our analysis, in spite of the relatively modest correlations between the two dietary methods, the Rhea follow-up FFQ and FR showed relatively good agreement in ranking participants based on their food and nutrient intakes. The degree of misclassification was overall small, while the majority 
Table 3 Cross-classification of participants by tertiles of calculated daily food group and nutrient intakes from the FFQ and the $3 \mathrm{~d}$ food record (FR) among pre-school children (fifty-one boys and forty-eight girls) in the validation study of the mother-child 'Rhea' birth cohort, Heraklion, Crete, Greece, 2011-2012

\begin{tabular}{|c|c|c|c|c|c|}
\hline & \multicolumn{3}{|c|}{ Agreement of tertiles for food groups and nutrients } & \multirow[b]{2}{*}{$\begin{array}{c}\text { Weighted } \\
\text { kappa }\left(\kappa_{\mathrm{w}}\right) \dagger\end{array}$} & \multirow[b]{2}{*}{$95 \% \mathrm{Cl}$} \\
\hline & $\begin{array}{c}\text { Correctly } \\
\text { classified (\%) }\end{array}$ & $\begin{array}{c}\text { Adjacent } \\
\text { classified (\%) }\end{array}$ & $\begin{array}{c}\text { Grossly } \\
\text { misclassified (\%) }\end{array}$ & & \\
\hline \multicolumn{6}{|l|}{ Food groups } \\
\hline Sugar preserves and confectionery $(\mathrm{g})$ & $49 \cdot 0$ & $39 \cdot 8$ & $11 \cdot 2$ & $0.37^{*}$ & $0.23,0.44$ \\
\hline Vegetables $(\mathrm{g})$ & 43.4 & 39.5 & $17 \cdot 1$ & $0 \cdot 21^{*}$ & $0.05,0.31$ \\
\hline Fruits $(\mathrm{g})$ & 58.5 & $36 \cdot 1$ & 5.4 & $0.57^{*}$ & $0.53,0.63$ \\
\hline Pulses (g) & $47 \cdot 0$ & $41 \cdot 2$ & $11 \cdot 8$ & $0.31^{*}$ & $0.20,0.45$ \\
\hline Milk (g) & 58.5 & 38.5 & 3.0 & $0.62^{*}$ & $0.47,0.73$ \\
\hline Poultry (g) & $36 \cdot 5$ & $47 \cdot 3$ & $16 \cdot 2$ & 0.12 & $0.00,0.20$ \\
\hline Red meat $(\mathrm{g})$ & 44.7 & 39.7 & $15 \cdot 6$ & $0 \cdot 17^{\star}$ & $0.06,0.32$ \\
\hline Eggs $(g)$ & $45 \cdot 5$ & $44 \cdot 3$ & $10 \cdot 2$ & $0.36^{*}$ & $0.16,0.42$ \\
\hline \multicolumn{6}{|l|}{ Nutrients } \\
\hline Protein $(\mathrm{g})$ & 38.4 & $48 \cdot 4$ & $13 \cdot 2$ & $0.24^{*}$ & $0.15,0.32$ \\
\hline Carbohydrate (g) & 39.4 & $46 \cdot 4$ & 14.2 & $0.23^{*}$ & $0.10,0.42$ \\
\hline Total fat $(\mathrm{g})$ & 38.4 & $46 \cdot 4$ & $15 \cdot 2$ & $0.20^{*}$ & $0.01,0.34$ \\
\hline MUFA (per $100 \mathrm{~g}$ ) & 41.4 & $40 \cdot 4$ & 18.2 & 0.15 & $0.01,0.32$ \\
\hline PUFA (per $100 \mathrm{~g}$ ) & $47 \cdot 5$ & $42 \cdot 4$ & $10 \cdot 1$ & $0.38^{*}$ & $0.28,0.53$ \\
\hline SFA (per $100 \mathrm{~g})$ & 43.4 & $36 \cdot 4$ & $20 \cdot 2$ & 0.12 & $0.01,0.28$ \\
\hline Vitamin $B_{12}(\mu \mathrm{g})$ & $52 \cdot 5$ & 38.4 & $9 \cdot 1$ & $0.44^{*}$ & $0.39,0.52$ \\
\hline Vitamin C (mg) & 39.4 & $50 \cdot 5$ & $10 \cdot 1$ & $0.32^{*}$ & $0.20,0.40$ \\
\hline Folate $(\mu \mathrm{g})$ & 43.4 & 44.4 & $12 \cdot 2$ & $0.30^{*}$ & $0.21,0.40$ \\
\hline $\mathrm{Zn}(\mathrm{mg})$ & 43.4 & $42 \cdot 4$ & $14 \cdot 2$ & $0.26^{*}$ & $0.03,0.44$ \\
\hline $\mathrm{Ca}(\mathrm{mg})$ & 49.5 & $38 \cdot 4$ & $12 \cdot 1$ & $0.35^{\star}$ & $0.19,0.39$ \\
\hline $\mathrm{Fe}(\mathrm{mg})$ & $37 \cdot 3$ & $46 \cdot 5$ & $16 \cdot 2$ & $0 \cdot 17^{\star}$ & $0.03,0.24$ \\
\hline lodine $(\mu \mathrm{g})$ & 58.6 & $32 \cdot 3$ & $9 \cdot 1$ & $0.48^{\star}$ & $0.32,0.59$ \\
\hline$P(m g)$ & $53 \cdot 6$ & $32 \cdot 2$ & $14 \cdot 2$ & $0.33^{*}$ & $0.17,0.53$ \\
\hline
\end{tabular}

Correctly classified if classified into the same tertile and grossly misclassified if classified into opposing tertiles.

${ }^{*}$ Statistically significant $\kappa_{\mathrm{w}}(P<0.05)$.

$\dagger \kappa_{\mathrm{w}}$ analysis of the agreement between the FFQ and the FR was undertaken on energy-adjusted data, using Fleiss-Cohen quadratic weight.

of participants (88\%) were classified into the same or adjacent tertiles for both food groups and nutrients.

The moderate agreement found between the two dietary methods was also attested by the Bland-Altman technique. The plots for energy, fat and carbohydrate intakes suggest that the mean differences between the FFQ and FR are similar not only at low but also at high intakes, with the limits of agreement wide for energy intake. This was also observed in all plots for nutrients and food groups (data not shown), except for fruits and vegetables where the mean differences increased at high intake. Furthermore, the test for heteroscedasticity showed no significant correlations $(P>0.05)$. Overall, the plots showed a small positive mean difference for food groups and nutrients between the two dietary methods, indicating that the Rhea 4 years FFQ tended to slightly overestimate food group and nutrient intakes compared with the FR. Nevertheless, the overestimation of nutrients suggested by the Rhea 4 years FFQ in the present study is in agreement with previous studies ${ }^{(12,24,26)}$.

The energy adjustment method was used in order to reduce dietary method error and to avoid misleading conclusions based on the differences found in total energy intake among participants. In fact, the energy-adjusted correlation coefficients were higher than the crude for almost all food groups and nutrients. In this analysis, we excluded those food groups with very low consumption ( $<50 \%$ of study participants).
The degree of agreement between the FFQ and FR could also be affected by parameters such as time span covered by the dietary tool, the ability to record seasonality and day-today variability ${ }^{(28)}$. In particular, the great variation in dietary intake is more pronounced in children, leading to weakened agreement between the different dietary tools used ${ }^{(29)}$. Finally, a limitation of validation studies is that they are not applicable to other populations ${ }^{(30)}$.

\section{Conclusion}

In summary, the present validation study indicates that the Rhea 4 years FFQ produces a realistic and relatively precise estimate of habitual intakes of food groups and nutrients among pre-school children in Crete, Greece.

\section{Acknowledgements}

Financial support: This project was co-financed by the European Union and the Hellenic Ministry of Health, 'Program of prevention and early diagnosis of obesity and neurodevelopment disorders in preschool age children in the prefecture of Heraklion, Crete, Greece' (NSRF 2007-2013 project, MIS 349580). The European Union and the Hellenic Ministry of Health \& Social Solidarity had no role in the design, analysis or writing of this article. Conflict of interest: 
None. Authorship: V.L. was the field study co-coordinator, participated in the statistical analysis and wrote the first draft of the paper; V.G. supervised the statistical analysis and helped with the data interpretation and manuscript preparation; L.C. supervised the data collection and provided feedback and critical revision of the manuscript; K.S. participated in the design of the study, helped with data interpretation and manuscript preparation, and provided critical review of the manuscript. Ethics of human subject participation: The study was conducted according to the guidelines laid down in the Declaration of Helsinki and all procedures involving human subjects were approved by the ethical committee of the University Hospital in Heraklion, Crete, Greece. Written informed consent was obtained from all women participating in the study.

\section{References}

1. Koletzko B, Brands B, Poston L et al. (2012) Early nutrition programming of long-term health. Proc Nutr Soc $\mathbf{7 1}$, 371-378.

2. Hussain A, Claussen B, Ramachandran A et al. (2007) Prevention of type 2 diabetes: a review. Diabetes Res Clin Pract 76, 317-326.

3. Flock MR \& Kris-Etherton PM (2011) Dietary Guidelines for Americans 2010: implications for cardiovascular disease. Curr Atheroscler Rep 13, 499-507.

4. Osler M (2002) Nutritional modification of cardiovascular disease risk. Int Congr Ser 1229, 109-111.

5. Johnson L, Mander AP, Jones LR et al. (2008) Energy-dense, low-fiber, high-fat dietary pattern is associated with increased fatness in childhood. Am J Clin Nutr 87, 846-854.

6. Reilly JJ, Armstrong J, Dorosty AR et al. (2005) Early life risk factors for obesity in childhood: cohort study. BMJ $\mathbf{3 3 0}$, 1357.

7. Becton LJ, Shatat IF \& Flynn JT (2012) Hypertension and obesity: epidemiology, mechanisms and clinical approach. Indian J Pediatr 79, 1056-1061.

8. Labarthe DR, Eissa M \& Varas C (1991) Childhood precursors of high blood pressure and elevated cholesterol. Annu Rev Public Health 12, 519-541.

9. Rosenlund H, Kull I, Pershagen G et al. (2011) Fruit and vegetable consumption in relation to allergy: disease-related modification of consumption? J Allergy Clin Immunol 127, $1219-1225$

10. Chatzi L, Torrent M, Romieu I et al. (2007) Diet, wheeze, and atopy in school children in Menorca, Spain. Pediatr Allergy Immunol 18, 480-485.

11. Vergnaud AC, Romaguera D, Peeters PH et al. (2013) Adherence to the World Cancer Research Fund/American Institute for Cancer Research guidelines and risk of death in Europe: results from the European Prospective Investigation into Nutrition and Cancer cohort study. Am J Clin Nutr 97, $1107-1120$

12. Treiber FA, Leonard SB, Frank G et al. (1990) Dietary assessment instruments for preschool children: reliability of parental responses to the 24-hour recall and a food frequency questionnaire. J Am Diet Assoc 90, 814-820.

13. Watson JF, Collins CE, Sibbritt DW et al. (2009) Reproducibility and comparative validity of a food frequency questionnaire for Australian children and adolescents. Int J Behav Nutr Phys Act 6, 62 .

14. Kobayashi T, Kamimura M, Imai S et al. (2011) Reproducibility and validity of the food frequency questionnaire for estimating habitual dietary intake in children and adolescents. Nutr J 10, 27.

15. Subar AF, Thompson FE, Kipnis V et al. (2001) Comparative validation of the Block, Willett, and National Cancer Institute food frequency questionnaires: the Eating at America's Table Study. Am J Epidemiol 154, 1089-1099.

16. Schatzkin A, Kipnis V, Carroll RJ et al. (2003) A comparison of a food frequency questionnaire with a 24-hour recall for use in an epidemiological cohort study: results from the biomarker-based Observing Protein and Energy Nutrition (OPEN) study. Int J Epidemiol 32, 1054-1062.

17. Willett W (2001) Commentary: dietary diaries versus food frequency questionnaires - a case of undigestible data. Int J Epidemiol 30, 317-319.

18. Chatzi L, Plana E, Daraki V et al. (2009) Metabolic syndrome in early pregnancy and risk of preterm birth. Am J Epidemiol 170, 829-836

19. Bland JM, Altman DG (1986) Statistical methods for assessing agreement between two methods of clinical measurement. Lancet 1, 307-310.

20. Fleiss JL \& Cohen J (1973) The equivalence of weighted kappa and the intraclass correlation coefficient as measures of reliability. Educ Psychol Meas 33, 613-619.

21. Landis JR \& Koch GG (1977) The measurement of observer agreement for categorical data. Biometrics 33, 159-174.

22. Willett WC (1998) Nutritional Epidemiology. New York: Oxford University Press.

23. Blum RE, Wei EK, Rockett HR et al. (1999) Validation of a food frequency questionnaire in Native American and Caucasian children 1 to 5 years of age. Matern Child Health J 3, 167-172.

24. Parrish LA, Marshall JA, Krebs NF et al. (2003) Validation of a food frequency questionnaire in preschool children. Epidemiology 14, 213-217.

25. Wilson AM \& Lewis RD (2004) Disagreement of energy and macronutrient intakes estimated from a food frequency questionnaire and 3-day diet record in girls 4 to 9 years of age. J Am Diet Assoc 104, 373-378.

26. Stein AD, Shea S, Basch CE et al. (1992) Consistency of the Willett semiquantitative food frequency questionnaire and 24-hour dietary recalls in estimating nutrient intakes of preschool children. Am J Epidemiol 135, 667-677.

27. Garrow JS (1995) Validation of methods for estimating habitual diet: proposed guidelines. Eur J Clin Nutr 49, 231-232.

28. Cade J, Thompson R, Burley V et al. (2002) Development, validation and utilisation of food-frequency questionnaires a review. Public Health Nutr 5, 567-587.

29. Nelson M, Black AE, Morris JA et al. (1989) Between- and within-subject variation in nutrient intake from infancy to old age: estimating the number of days required to rank dietary intakes with desired precision. Am J Clin Nutr 50, 155-167.

30. Plummer M \& Kaaks R (2003) Commentary: An OPEN assessment of dietary measurement errors. Int J Epidemiol 32, 1062-1063. 